\title{
Quality of life, pain, and functional respiratory recovery after lobectomy for early stage non-small cell lung cancer: a review of the literature comparing minimal invasive and open procedures
}

\author{
Goussens Alexandre, Lacroix Valérie \\ Department of cardiovascular and thoracic surgery, Cliniques Universitaires Saint Luc, Brussels 1200, Belgium.
}

Correspondence to: Dr. Lacroix Valérie, Department of cardiovascular and thoracic surgery, Cliniques universitaires Saint Luc, Avenue Hippocrate 10, Bruxelles 1200,Belgium. E-mail: valerie.lacroix@uclouvain.be

How to cite this article: Alexandre G, Valérie L. Quality of life, pain, and functional respiratory recovery after lobectomy for early stage non-small cell lung cancer: a review of the literature comparing minimal invasive and open procedures. Miniinvasive Surg 2020;4:35. http://dx.doi.org/10.20517/2574-1225.2020.07

Received: 10 Jan 2020 First Decision: 10 Mar 2020 Revised: 12 Mar 2020 Accepted: 19 Mar 2020 Published: 18 Jun 2020

Science Editor: Giulio Belli Copy Editor: Jing-Wen Zhang Production Editor: Tian Zhang

\begin{abstract}
The recent improvement in surgical techniques for non-small cell lung cancer enables evident better results in term of postoperative recovery with lower adverse events. Even though the interest in minimally invasive procedures has increased, more subjective advantages are not always so apparent in the literature. There is indeed a growing interest in the daily life of patients including their management of physical and emotional pain, the perception of quality of life, and pulmonary function recovery. This review aims to highlight the advantages of minimal invasive surgery on pain, quality of life, and functional pulmonary recovery after lobectomy alone for early stage non-small cell lung cancer. Minimal invasive techniques or limited sparing open techniques offer better results in term of postoperative pain than open nonsparing techniques, allowing a lighter analgesia protocol. However, these clear benefits seem to disappear in the midterm postoperative period. Studies suggest that minimal invasive surgery is non-inferior to thoracotomy in terms of quality of life, and seems to give patients at least a better vision of their health, but larger-scale studies are needed to demonstrate its superiority. Data show clear advantages in the postoperative pulmonary function recovery for minimal invasive surgery compared to that of open procedures, although sparing and anterior incisions can show equivalence. That benefit does not seem to persist in the mid and long term. Nevertheless, the posterolateral thoracotomy appears to have the worse effect on the loss of pulmonary function.
\end{abstract}

Keywords: Lobectomy, lung cancer, quality of life, pain, pulmonary function

\footnotetext{
(ㄷ) $\odot$

(C) The Author(s) 2020. Open Access This article is licensed under a Creative Commons Attribution 4.0 International License (https://creativecommons.org/licenses/by/4.0/), which permits unrestricted use, sharing, adaptation, distribution and reproduction in any medium or format, for any purpose, even commercially, as long as you give appropriate credit to the original author(s) and the source, provide a link to the Creative Commons license, and indicate if changes were made.
}

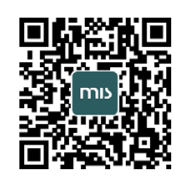




\section{INTRODUCTION}

Lobectomy for early stage non-small cell lung cancer has been described in the last decade with a large variety of approaches ${ }^{[1]}$. Open surgery can be performed by an anterior, axillary, or posterolateral incision. Muscle-sparing techniques have recently been adopted to limit the thoracic trauma. The development of video-assisted thoracoscopic surgery (VATS) first enabled reducing the size of the thoracotomy, usually anterior, and is actually limited to the trocar incisions or a single portal approach. More recently, robotic assisted surgery (RATS) offers better ergonomics as well as three-dimensional imaging ${ }^{[2,3]}$. Despite many papers encouraging clear benefits on pain for minimally invasive techniques, criticism must be made of the compared surgical open methods, mostly involving non-sparing techniques.

In this paper, we focus on pain, quality of life, and functional pulmonary recovery after lobectomy for early stage non-small cell lung cancer depending on the surgical technique. This represents an important aspect in the rise of patients' involvement in their own care ${ }^{[4]}$.

Relevant studies were obtained by searching the PubMed and Uptodate databases until 31 October 2019. The search terms included "lung cancer" AND "lobectomy" AND "pain" OR "quality of life" OR "pulmonary function" in the title, abstract, and keywords. Tables 1 and 2 summarize characteristics and operative details of the cited articles.

\section{PAIN}

Pain assessment is subjective and depends on the personal tolerance, culture, and psychological context. The postoperative analgesia protocol will influence the results. Pain is an important factor because it can result in hard coughing and mobilization, leading to potential secondary pneumonia. Pain management after surgery is obviously a basic principle in current medical care. Having pain at the surgery site for more than two months is considered as chronic pain.

Analgesia can be provided by epidural or para-spinal catheter placed before surgery; inter-costal nerve block, para-vertebral catheter, or wound infiltration during surgery; and patient-controlled/not controlled intravenous analgesics, intramuscular, oral, or suppository postoperatively. Catheter analgesics are usually stopped after removal of the thoracic drain.

The most used questionnaires for pain are the Visual Pain Score, the Visual Analog Scale, and the Numerical Rating Scale ${ }^{[5]}$. In addition, chronic pain can be evaluated by the Pain Detected Questionnaire.

Several studies showed clear benefit on pain from minimal invasive techniques compared to non-sparing thoracotomies: a prospective study ${ }^{[6]}$ showed a significant decrease of the postoperative pain at Days 0,1 , 7, and 14 in a VATS group (two trocars with a $7-\mathrm{cm}$-long anterior incision) compared to a non-sparing posterolateral thoracotomy group (with one or two ribs resection and no muscle sparing). All patients had an epidural catheter. A similar retrospective study ${ }^{[7]}$ showed a significant decrease in the postoperative pain in a VATS procedure (6-cm anterior access incision and three trocars) compared to an anterolateral thoracotomy (12 cm long with a section of a costal cartilage but muscle sparing) at the first week after surgery. That difference disappeared in the second postoperative week. A continuous epidural analgesia was present for every patient until the third postoperative day.

A prospective randomized study ${ }^{[8]}$ compared VATS (with three-trocar technique and a 4-cm anterior utility incision) and anterolateral thoracotomy (16- $\mathrm{cm}$ incision) with muscle and rib sparing, every patient receiving an epidural catheter. They assessed the postoperative pain by Numerical Rating Scale at 2, 4, 8, 12, 26, and 52 weeks and found a significantly lower level of pain in the VATS group during the entire follow- 
Table 1. Main characteristics of publications related to pain and respiratory recovery after lobectomy

\begin{tabular}{|c|c|c|c|c|c|c|c|}
\hline First author & Published & Country & Subject & Period & $n$ & Type & $\begin{array}{c}\text { Comparison } \\
\text { groups }\end{array}$ \\
\hline Kwon et al. ${ }^{[11]}$ & 2017 & USA & Pain (VPS and PDQ) & $2010-2014$ & 502 & Retrospective & $\begin{array}{l}\text { RATS vs. VATS } \\
v s \text {. open }\end{array}$ \\
\hline Van der Ploeg et al. ${ }^{[12]}$ & 2019 & The Nederlands & Pain (NRS) & $2015-2016$ & 57 & Retrospective & $\begin{array}{l}\text { RATS vs. VATS } \\
\text { vs. open }\end{array}$ \\
\hline Nakata et al. ${ }^{[23]}$ & 2000 & Japan & $\begin{array}{l}\text { Respiratory function } \\
\text { (arterial blood gaz, FVC, } \\
\text { FEV1 and PFR) }\end{array}$ & $\begin{array}{l}\text { Nov 1996-Aug } \\
1997\end{array}$ & 21 & Retrospective & VATS vs. open \\
\hline Nomori et al. ${ }^{[24]}$ & 2003 & Japan & $\begin{array}{l}\text { Respiratory function (VC } \\
\text { and } 6 \mathrm{MWT} \text { ) }\end{array}$ & $1991-2000$ & 112 & Retrospective & VATS vs. open \\
\hline Nagahiro et al. ${ }^{[6]}$ & 2001 & Japan & $\begin{array}{l}\text { Pain (VAS) and respiratory } \\
\text { function (VC, FVC and } \\
6 \mathrm{MWT} \text { ) }\end{array}$ & $\begin{array}{l}\text { Jun 1999-Apr } \\
2000\end{array}$ & 22 & $\begin{array}{l}\text { Prospective non } \\
\text { randomized }\end{array}$ & VATS vs. open \\
\hline Handy et al. ${ }^{[10]}$ & 2009 & USA & $\begin{array}{l}\text { Pain (VAS), QOL (SF36) } \\
\text { and respiratory function } \\
\text { (FEV1 and 6MWT) }\end{array}$ & 1998-2007 & 241 & Retrospective & VATS vs. open \\
\hline Bendixen et al..$^{[8]}$ & 2016 & Denmark & $\begin{array}{l}\text { Pain (NRS) and QOL } \\
\text { (EQ5D and EORTC } \\
\text { QLQ-C30) }\end{array}$ & $\begin{array}{l}\text { Oct 2008-Aug } \\
2014\end{array}$ & 206 & $\begin{array}{l}\text { Prospective } \\
\text { randomized }\end{array}$ & VATS vs. open \\
\hline Nomori et al. ${ }^{[7]}$ & 2001 & Japan & $\begin{array}{l}\text { Pain (VAS) and respiratory } \\
\text { function (VC, } 6 \mathrm{MWT} \\
\text { and respiratory muscle } \\
\text { strength) }\end{array}$ & $\begin{array}{l}\text { Aug 1999-Dec } \\
2000\end{array}$ & 66 & Retrospective & VATS vs. open \\
\hline Andreetti et al. ${ }^{[9]}$ & 2014 & Italy & Pain (VAS) & $\begin{array}{l}\text { Apr 2011-Jan } \\
2013\end{array}$ & 145 & $\begin{array}{l}\text { Prospective non } \\
\text { randomized }\end{array}$ & VATS vs. open \\
\hline
\end{tabular}

VPS: visual pain score; PDQ: pain detected questionnaire; NRS: numerical rating scale; FVC: forced vital capacity; FEV1: forced expiratory volume in $1 \mathrm{sec}$; PFR: peak flow rate; 6MWT: 6 min walking test; VAS: visual analog scale; EQ5D: euroQol 5 dimensions; EORTC QLQ-C30: european organisation for research and treatment of cancer 30 item quality of life questionnaire

up. A comparable prospective study ${ }^{[9]}$ evaluated pain by Visual Analog Scale at 1, 12, 24, and 48 h between VATS (three-trocar technique and an anterior access incision of $4 \mathrm{~cm}$ ) and anterolateral thoracotomy (a 9-10-cm incision) with muscle and rib sparing, showing a significantly lower level of pain for VATS. All patients benefited from an intercostal nerve block and continuous intra-venous analgesia.

Mid-term evaluation has been reported ${ }^{[10]}$ with no significant difference in the pain level (using Visual Analog Scale) at six months between open procedures (thoracotomy with muscle sparing or median sternotomy) and VATS (a three-trocar technique with an anterior 5-6-cm incision). Although the pain level was the same, there was a significantly lower consumption of painkillers in the VATS group.

An interesting retrospective study ${ }^{[11]}$ compared RATS, VATS, and posterolateral thoracotomy (PLT) in terms of pain from the first to the ninth postoperative day (by Visual Pain Score) and at two months (by Pain Detected Questionnaire). The RATS consisted in a $4+1$-port technique while the VATS was a threeor four-port technique, with an access incision less than $5 \mathrm{~cm}$ long. The PLT was mostly serratus sparing with resection of the sixth rib. Thoracotomies benefited from epidural or para-spinous catheter while minimal invasive surgery (MIS) had intercostal nerve block and PCA. The study showed no significant difference for acute or chronic pain between VATS and RATS, but a significant difference between MIS and thoracotomy starting at Postoperative Day 4. Concerning the chronic pain, no significant difference was noticed between MIS and thoracotomy.

A similar study ${ }^{[12]}$ also evaluated minimally invasive approaches (VATS and RATS) and anterolateral thoracotomy (ALT) at Postoperative Day 1, 3, and 5 via Numerical Rating Scale. All patients benefited from thoracic epidural analgesia. The RATS used $4+1$ ports, the VATS three trocars with a 4 -cm anterior utility incision, and the anterolateral thoracotomy was $20 \mathrm{~cm}$ long with muscle sparing but no rib resection. There 


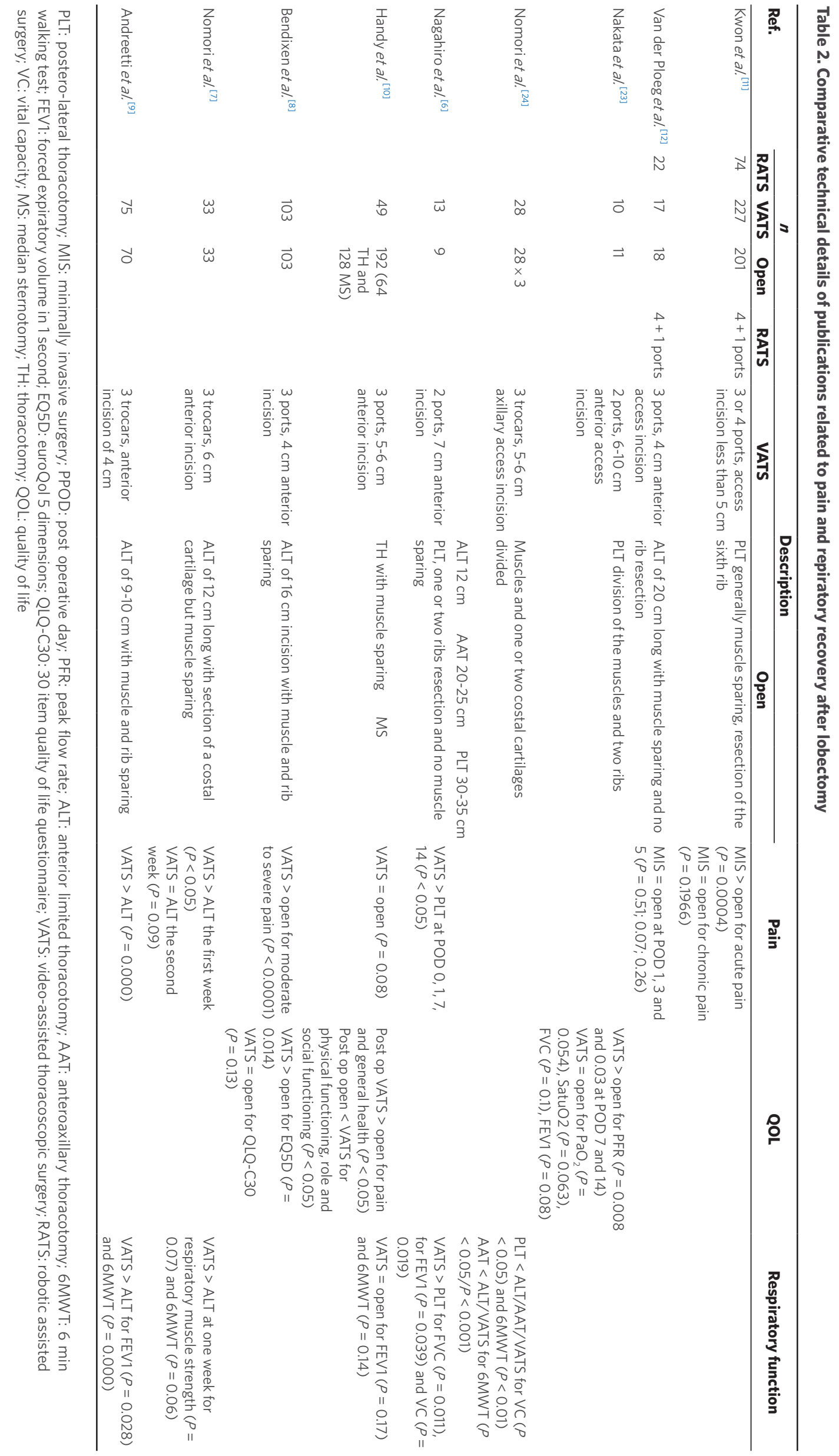


were no significant differences on pain among the surgical techniques; a non-significant benefit for RATS was noticed.

The technical details for the RATS and VATS procedures are quite similar considering the number of ports (2-4 for VATS and $4+1$ for RATS) and the length of the access incision $(4-7 \mathrm{~cm})$. The number of ports does not seem to impact the postoperative pain ${ }^{[13]}$. However, thoracotomy techniques greatly vary, with anterior or posterior incisions, and muscle/rib sparing or non-sparing techniques. Non-randomized studies usually indicated small and peripheral tumors for MIS, while open procedures were performed for larger and central tumors.

We can conclude that, in the early postoperative period, minimal invasive techniques or limited sparing open techniques offer better results with respect to pain compared to large and non-sparing open techniques. The MIS techniques allow a lighter analgesia protocol. However, the clear benefits on pain from the MIS seem to disappear in the mid-term postoperative period.

\section{QUALITY OF LIFE}

Quality of life is defined by the World Health Organization as "individual's perceptions of their position in life in the context of their culture and value systems in which they live and in relation to their goals, expectations, standards and concerns" ${ }^{\text {"[14] }}$. We focus here on how daily life is impacted by the surgery.

Two questionnaires are mainly used for this assessment: the Short Form 36 Health Survey (SF36) and the European Organization for Research and Treatment of Cancer 30-Items Quality Of Life Questionnaire (EORTC QLQ C30) ${ }^{[15-18]}$. The first one evaluates patients on both physical and emotional component scales that can be compared to the healthy population. The second one is more focused on the cancer population and evaluates the impact of the disease and its treatment on the daily life.

A prospective study ${ }^{[19]}$ described a one-month temporary decrease in quality of life (QOL) functioning scores (EORTC QLQ C30) after lobectomy, with concomitant increase in pain and dyspnea. The scores return to baseline at three months postoperatively. Comparing thoracotomy to VATS, significant differences are seen in favor of VATS in this study. Antero- and posterolateral thoracotomy are comparable for QOL evolution.

However, while improvements in QOL have been demonstrated in a few studies in favor of MIS, there is no current evidence supporting its superiority. A retrospective study ${ }^{[9]}$ compared the quality of life between VATS and open procedures (median sternotomy and muscle sparing thoracotomies) preoperatively and at six months after the surgery using the SF36 questionnaire. It showed no significant difference at 6 months. However, in the VATS group, a significant improvement at 6 months is described for bodily pain and general health compared to the preoperative status. Regarding the open group, a significant worsening is highlighted after the surgery on the physical functioning, role, and social functioning.

A prospective study ${ }^{[20]}$ using SF36 every four months after surgery for 12 months showed similar physical component summary between VATS and thoracotomy during the first 12 months after surgery, with a mental component summary score worse in the VATS group at four and eight months. Such results might be explained by the higher expectations by the patients for MIS.

A quite exhaustive protocol study ${ }^{[8]}$ evaluated two questionnaires [EuroQol 5 Dimensions (EQ5D) and EORTC QLQ C30] at 2, 4, 8, 12, 26, and 52 weeks after surgery (VATS and anterolateral thoracotomy). EQ5D questionnaire evaluated mobility, self-care, usual activities, pain and discomfort, anxiety, and depression. The scores for EQ5D were significantly better during the entire follow up for the VATS group while there was no significant difference for the EORTC QLQ C30 between VATS and open surgery. The 
emotional function was the only subgroup where VATS was significantly better than open in the EORTC QLQ C30.

Robotic surgery was evaluated with the SF-12 questionnaire at three weeks and four months in a propensity-matched analysis ${ }^{[21]}$ considering rib and nerve sparing thoracotomies. Patients reported better QOL scores in the RATS group. In particular, a higher mental QOL score three weeks postoperatively was noticed. A similar trend was observed for physical QOL without statistical significance. At four months, there was no difference between the two groups.

The major difficulty concerning QOL assessment is the important interaction between pain and respiratory function. In conclusion, studies suggest that MIS is non-inferior to thoracotomy in terms of QOL, and seem to give patients at least a better vision of their health, but larger-scale studies are needed to demonstrate its superiority.

\section{RESPIRATORY FUNCTION RECOVERY}

Pulmonary function is objectively evaluated in the postoperative period by the Vital Capacity (VC) or Forced Vital Capacity (FVC) and the Forced Expiratory Volume in one second (FEV1). A more practical evaluation can also be performed with the 6 Minutes Walking Test $(6 \mathrm{MWT})^{[22]}$. The preoperative pulmonary function is mandatory to measure its evolution postoperatively. One must keep in mind that patients who undergo VATS are often selected because they have worse preoperative conditions.

Studies evaluating VATS and non-sparing thoracotomies clearly show superiority for MIS. VATS and $\mathrm{PLT}^{[23]}$ were compared in terms of arterial blood gas analyses $\left(\mathrm{PaO}_{2}\right.$ and $\left.\mathrm{PaCO}_{2}\right)$ at 4 , 7, and 14 days after surgery and the pulmonary function (FVC, FEV1, and Peak Flow Rate) at 7 and 14 days, as well as at one year. The VATS consisted in a 6-10-cm anterior access incision with two trocars while the PLT divided the muscles and two ribs. Only patients from the PLT group benefitted from a continuous epidural anesthesia. They observed no significant difference concerning the arterial blood gas analyses between the two groups. Pulmonary testing was significantly better for VATS at Days 7 and 14. There was no difference at one year between the two groups. Another study also demonstrated significant benefit for VATS ${ }^{[6]}$ when comparing VC, FVC, and FEV1 at one and two weeks postoperative between VATS and posterolateral thoracotomy with muscle division and one rib resection.

VATS and various thoracotomy approaches were compared with the VC parameter measured at 1, 2, 4, 12, and 24 weeks after surgery, and the $6 \mathrm{MWT}$ at one week ${ }^{[24]}$. They performed VATS with a 5-6-cm axillary incision and three trocars, while the thoracotomies always divided the concerned muscles and one or two costal cartilages (anterolateral, axillary, and posterolateral approach). The lengths of the incisions were, respectively, 12, 20-25, and $30-35 \mathrm{~cm}$. All patients benefited from a continuous epidural analgesia. They also noted a clear significant disadvantage in the posterolateral group regarding VC and 6MWT. VATS, anterolateral, and axillary approaches were not different in terms of VC during the follow-up while the 6MWT was significantly better in the VATS and anterolateral groups compared to axillary and posterolateral groups.

Equivalent results for VATS and anterolateral thoracotomy approaches have been confirmed ${ }^{[7]}$ with no difference in term of $\mathrm{VC}, 6 \mathrm{MWT}$, and respiratory muscle strength (measured with the maximal expiratory and inspiratory pressure ${ }^{[25]}$ at one and two weeks after VATS or anterolateral thoracotomy. However, other studies have demonstrated the opposite ${ }^{[9]}$ with a significant advantage of VATS in comparison with anterolateral, muscle sparing thoracotomy, concerning FEV1 and 6MWT at two days and one month after surgery. 
The mid-term impact has been studied ${ }^{[10]}$ using FEV1 and 6MWT at six months of VATS and open procedures, being thoracotomy or sternotomy. No significant difference has been demonstrated.

These data show advantages in the postoperative pulmonary function recovery for MIS compared to open procedures, although sparing and anterior incisions can show equivalence. That benefit does not seem to persist in the mid and long term. Nevertheless, the posterolateral thoracotomy appears to have the worse effect on the loss of pulmonary function.

\section{CONCLUSION}

We are now evolving to the era of minimal invasive surgery, not only for esthetic reasons but mainly to reduce the surgical stress of the procedures on our patients. There is scientific evidence for equivalent oncological control by minimal invasive as by open surgery ${ }^{[26]}$.

Through this review of the literature, we can assume that such equivalence seems evident concerning postoperative pain, quality of life, and respiratory function recovery, and the superiority of minimal invasive surgery may be assumed for the early postoperative period. These parameters are indeed quite subjective and interact with each other. Their evaluation needs compliance from the patients in the long run. Nowadays, smartphone applications may be a solution to improve follow-up.

\section{DECLARATIONS}

Authors' contributions

Wrote and reviewed: Goussens A, Lacroix V

\section{Availability of data and materials}

Not applicable.

\section{Financial support and sponsorship}

None.

\section{Conflicts of interest}

All authors declared that there are no conflicts of interest.

\section{Ethical approval and consent to participate}

Not applicable.

\section{Consent for publication}

Not applicable.

\section{Copyright}

(c) The Author(s) 2020.

\section{REFERENCES}

1. Lewis RJ, Sisler GE, Caccavale RJ. Imaged thoracic lobectomy: should it be done? Ann Thorac Surg 1992;54:80-3.

2. Moorthy K, Munz Y, Dosis A, Hernandez J, Martin S, et al. Dexterity enhancement with robotic surgery. Surg Endosc 2004;18:790-5.

3. Morgan JA, Ginsburg ME, Sonett JR, Morales DL, Kohmoto T, et al. Advanced thoracoscopic procedures are facilitated by computeraided robotic technology. Eur J Cardiothorac Surg 2003;23:883-7.

4. Cykert S, Kisling G, Hansen CJ. Patient preferences regarding possible outcomes of lung resection: what outcomes should preoperative evaluations target? Chest 2000;117:1551-9.

5. Williamson A, Hoggart B. Pain: a review of three commonly used pain rating scales. J Clin Nurs 2005;14:798-804.

6. Nagahiro I, Andou A, Aoe M, Sano Y, Date H, et al. Pulmonary function, postoperative pain, and serum cytokine level after lobectomy: 
a comparison of VATS and conventional procedure. Ann Thorac Surg 2001;72:362-5.

7. Nomori H, Horio H, Naruke T, Suemasu K. What is the advantage of a thoracoscopic lobectomy over a limited thoracotomy procedure for lung cancer surgery? Ann Thorac Surg 2001;72:879-84.

8. Bendixen M, Jørgensen OD, Kronborg C, Andersen C, Licht PB. Postoperative pain and quality of life after lobectomy via videoassisted thoracoscopic surgery or anterolateral thoracotomy for early stage lung cancer: a randomised controlled trial. Lancet Oncol 2016;17:836-44.

9. Andreetti C, Menna C, Ibrahim M, Ciccone AM, D’Andrilli A, et al. Postoperative pain control: videothoracoscopic versus conservative mini-thoracotomic approach. Eur J Cardiothorac Surg 2014;46:907-12.

10. Handy JR Jr, Asaph JW, Douville EC, Ott GY, Grunkemeier GL, et al. Does video-assisted thoracoscopic lobectomy for lung cancer provide improved functional outcomes compared with open lobectomy? Eur J Cardiothorac Surg 2010;37:451-5.

11. Kwon ST, Zhao L, Reddy RM, Chang AC, Orringer MB, et al. Evaluation of acute and chronic pain outcomes after robotic, videoassisted thoracoscopic surgery, or open anatomic pulmonary resection. J Thorac Cardiovasc Surg 2017;154:652-9.e1.

12. Van der Ploeg APT, Ayez N, Akkersdijk GP, van Rossem CC, de Rooij PD. Postoperative pain after lobectomy: robot-assisted, videoassisted and open thoracic surgery. J Robot Surg 2020;14:131-6.

13. Akter F, Routledge T, Toufektzian L, Attia R. In minor and major thoracic procedures is uniport superior to multiport video-assisted thoracoscopic procedures surgery? Interact Cardiovasc Thorac Surg 2015;20:550-5.

14. The World Health Organization Quality of Life assessment (WHOQOL): position paper from the World Health Organization. Soc Sci Med 1995;41:1403-9.

15. Ware JE Jr, Sherbourne CD. The MOS 36-item short-form health survey (SF-36). I. Conceptual framework and item selection. Med Care 1992;30:473-83.

16. Aaronson NK, Ahmedzai S, Bergman B, Bullinger M, Cull A, et al. The European Organization for Research and Treatment of Cancer QLQ-C30: a quality of life instrument for use in international clinical trials in oncology. J Natl Cancer Inst 1993;85:365-76.

17. Pompili C, Novoa N, Balduyck B; ESTS Quality of life and Patient Safety Working Group. Clinical evaluation of quality of life: a survey among members of European Society of Thoracic Surgeons (ESTS). Interact Cardiovasc Thorac Surg 2015;21:415-9.

18. Pompili C. Quality of life after lung resection for lung cancer. J Thorac Dis 2015;7:S138-44.

19. Balduyck B, Hendriks J, Lauwers P, Van Schil P. Quality of life evolution after lung cancer surgery: a prospective study in 100 patients. Lung Cancer 2007;56:423-31.

20. Riszk N, Ghanie A, Hsu M, Bains MS, Downey RJ, et al. A prospective trial comparing pain and quality of life measures after anatomic lung resection using thoracoscopy or thoracotomy. Ann Thorac Surg 2014;98:1160-6.

21. Cerfolio RJ, Bryant AS, Skylizard L, Minnich DJ. Initial consecutive experience of completely portal robotic pulmonary resection with 4 arms. J Thorac Cardiovasc Surg 2011;142:740-6.

22. Butland RJ, Pang J, Gross ER, Woodcock AA, Geddes DM. Two-, six-, and 12-minutes walking tests in respiratory disease. Br Med J (Clin Res Ed) 1982;284:1607-8.

23. Nakata M, Saeki H, Yokoyama N, Kurita A, Takiyama W, et al. Pulmonary function after lobectomy: video-assisted thoracic surgery versus thoracotomy. Ann Thorac Surg 2000;70:938-41.

24. Nomori H, Ohtsuka T, Horio H, Naruke T, Suemasu K. Difference in the impairment of vital capacity and 6-minute walking after a lobectomy performed by thoracoscopic surgery, an anterior limited thoracotomy, an anteroaxillary thoracotomy, and a posterolateral thoracotomy. Surg Today 2003;33:7-12.

25. Black LF, Hyatt RE. Maximal respiratory pressures: normal values and relationship to age and sex. Am Rev Respir Dis 1969;99:696702.

26. Stephens N, Rice D, Correa A, Hoffstetter W, Mehran R, et al. Thoracoscopic lobectomy is associated with improved short term and equivalent oncological outcomes compared with open lobectomy for clinical stage I non-small cell cancer: a propensity-matched analysis of 963 cases. Eur J Cardiothorac Surg 2014;46:607-13. 